\title{
CRISTIANISMO PAULINO EN HUARTE DE SAN JUAN: MERITOCRACIA Y LINAJE EN EL EXAMEN DE INGENIOS PARA LAS CIENCIAS (BAEZA 1575, 1594)*
}

\author{
POR \\ JON ARRIZABALAGA ${ }^{1}$ \\ IMF-CSIC, Barcelona \\ Y \\ MARIA LAURA GIORDANO \\ Universitat Abat Oliba CEU
}

RESUMEN

Este trabajo aborda los usos que Juan Huarte de San Juan hizo de la Biblia en el Examen de Ingenios para las Ciencias (Baeza, 1575 y 1594). Tras un breve apunte de su formación, primero en Baeza como licenciado en artes y luego en Alcalá, como doctor en medicina, se examina el recurso de Huarte al Pentateuco para reforzar su tesis - basada en la doctrina galénica de los temperamentos-, sobre la excelencia natural de los judíos para la práctica de la medicina. La segunda parte del artículo aborda el análisis de espiritualidad paulina en el autor del EIC. Esta última se convierte en una herramienta teórica para elaborar una crítica radical contra el proyecto de exclusión social de los cristianos nuevos, en una línea de continuidad con una tradición cristiana de pensamiento crítico muy viva en el mundo ibérico desde el siglo XV.

PALABRAS CLAVE: Juan Huarte de San Juan; exegesis bíblica; estatutos de limpieza de sangre, disidencia; conversos.

\section{PAULINE CHRISTIANISM OF HUARTE DE SAN JUAN: MERITOCRACY AND LINEAGE IN THE EXAMEN DE INGENIOS PARA LAS CIENCIAS (THE EXAMINATION OF MEN'S WITS, BAEZA 1575, 1594)}

\section{ABSTRACT}

This paper examines the uses that Juan Huarte de San Juan made of the Bible in the Examen de ingenios para las ciencias (The Examination of Men's Wits, Baeza, 1575 and 1594). After a brief summary of Huarte's education, firstly in Baeza, where he became a bachelor of arts, and, subsequently, in Alcalá, where he received the doctorate in medicine, the study focuses on his use of the Pentateuch to support his thesis - based on Galen's humour theory of temperament- of the natural excellence of the Jews for the practice of medicine. The second part of the article deals with Pauline spirituality in the author of Examen de ingenios para las ciencias. In Huarte's discourse, this spirituality becomes a theoretical tool to formulate a powerful attack on plans for the social exclusion of new Christians, in line with a Christian tradition of critical thinking that had been very much alive in the Iberian world since the fifteenth century.

KEY WORDS: Juan Huarte de San Juan; biblical exegesis; purity of blood statutes; dissidence; conversos.

Cómo CITAR ESTE ARTículo / CITATION: Arrizabalaga, Jon y Maria Laura Giordano. 2020. «Cristianismo paulino en Huarte de San Juan: meritocracia y linaje en el Examen de ingenios para las ciencias (Baeza 1575, 1594)». Hispania Sacra LXXII, 146: 363-375. https://doi.org/10.3989/hs.2020.025

Recibido/Received 17-01-2018

Aceptado/Accepted $\quad 04-03-2020$

\footnotetext{
El trabajo previo a la redacción de este artículo ha sido posible gracias a la participación de Maria Laura Giordano en el Proyecto Nacional de Investigación PGC2018-093827-B-.100 (FEDER/AEI).

1 jonarri@imf.csic.es / ORCID iD: https://orcid.org/0000-0002-0740-4951

2 giordano1@uao.es / ORCID iD: https://orcid.org/0000-0002-2341-3567
} 
"La sal [de la tierra] no tiene lugarteniente» Juan Huarte de San Juan (EIC, 711)

\section{INTRODUCCIÓN}

La figura de Juan Huarte de San Juan (San Juan del Pie del Puerto, c. 1529 - Baeza, c. 1588) está asociada a la fortuna editorial de su única obra escrita conocida, el Examen de ingenios para las ciencias (Baeza, 1575). ${ }^{3}$

Tal como señaló ya en su portada, ${ }^{4}$ Huarte quiso ofrecer en el EIC un estudio sistemático de las diferentes facultades intelectuales - los «ingenios»-que habilitaban a los hombres para aprender y practicar diferentes profesiones. Según su teoría de los ingenios, era posible identificar la clase de inteligencia propia de cada varón y determinar la disciplina ("ciencia») más idónea para aquella. Huarte no ocultaba que esta teoría se basaba en la doctrina de los temperamentos - tradicionalmente atribuida a Galeno, si bien solo desarrollada plenamente a lo largo de los siglos ulteriores a su muerte-, pero reclamaba su originalidad afirmando que nadie antes había nunca respondido "con distinción y claridad» a cuatro cuestiones cruciales que pretendía abordar en su trabajo: (1) qué hace a un varón hábil para una disciplina (arte o ciencia) y no para otra; (2) cuántos tipos diferentes de ingenio hay; (3) qué disciplinas se ajustan mejor a cada uno de ellos; y (4) a través de qué signos era posible conocer todo ello. ${ }^{5}$

Huarte desarrollaría hasta sus últimas consecuencias las nociones sobre las cualidades intelectuales y morales ligadas a los distintos temperamentos, contenidas en la obra galénica Quod animi mores corporis temperamenta insequantur. A su juicio, los diferentes ingenios para las ciencias dependen del temperamento corporal de cada individuo. Este temperamento se establece a partir de los cuatro humores y, sobre todo, de las cuatro cualidades primarias - los pares calorfrialdad y humedad-sequedad- y varía de acuerdo a diversos parámetros, entre ellos, el sexo, la etapa de la vida, el régimen de vida, la raza y el entorno físico. La amplia tipología de ingenios por él desarrollada tendría su fundamento doctrinal en las innumerables posibilidades que ofrece la combinación de todos estos elementos en sus diversas variables. La aplicación de esta tipología de los ingenios al entorno socio-cultural en el que transcurrió su existencia, brindaría una proyección

3 En la preparación de este trabajo hemos utilizado la edición anotada del Examen de ingenios para las ciencias de Juan Huarte de San Juan, a cargo de Guillermo Serés (Huarte de San Juan 1989 133-723). Salvo que se indique otra cosa, todas las citas a la obra de Huarte remiten a esta edición, a la que nos referiremos de modo abreviado como EIC.

4 «Examen de ingenios, para las sciencias. Donde se muestra la differencia de habilidades que ay en los hombres, y el género de letras que a cada uno responde en particular. Es obra donde el que leyere con attención hallará la manera de su ingenio, y sabrá escoger la sciencia en que más ha de aprovechar; y si por ventura la uviese ya professado, entenderá si atinó a la que pedía su habilidad natural».

5 «Todos los filósofos antiguos hallaron por experiencia que donde no hay naturaleza que disponga al hombre a saber, por demás es trabajar en las reglas del arte. Pero ninguno ha dicho con distinción ni claridad qué naturaleza es la que hace al hombre hábil para una ciencia y para otra incapaz, ni cuántas diferencias de ingenio se hallan en la especie humana, ni qué artes y ciencias responden a cada uno en particular, ni con qué señales se había de conocer, que era lo que más importaba» (EIC, 153-154). sistemática y creativa de estos ingenios a las ocupaciones de las elites en las sociedades del Antiguo Régimen, muy destacadamente las profesiones universitarias. Ello ayuda a explicar el éxito editorial del EIC en toda Europa hasta bien entrado el siglo XVIII.

La editio princeps del EIC (Baeza 1575) incluía quince capítulos, que se vieron ampliados hasta veintidós en la nueva edición de 1594 - redactada a resultas de la censura inquisitorial de que aquella fue objeto-, por la adición de dos nuevos capítulos al inicio de la obra, la supresión del capítulo séptimo, y la división del extenso capítulo último en seis más breves. En los siete primeros capítulos de la primera edición se expone la base doctrinal de su teoría de los ingenios, en el octavo se ofrece una clasificación de las ciencias conforme a los ingenios más propicios para cada una de ellas, y en el decimoquinto se suministran consejos prácticos a los padres para que puedan generar y educar hijos (varones) «sabios y del ingenio que requieren las letras» (EIC, 601); en los seis capítulos restantes (del IX al XIV) Huarte aplicó su teoría a diferentes profesiones y oficios a través de los sucesivos ejemplos de las humanidades, la teología, las leyes, la medicina, el arte militar y el «oficio de rey».

Huarte dedicó el EIC al rey Felipe II, a quien instaba a intervenir en el acceso de los estudiantes a las facultades universitarias estableciendo medidas basadas en su teoría, que permitieran seleccionar solo a los varones con los ingenios más adecuados a cada facultad. Apoyándose en las nociones sobre la organización social más conveniente a la república, que Platón había dispuesto en sus Leyes, Huarte asignaba al médico teórico (es decir, a sí mismo) la posición de consejero privilegiado del príncipe y "experto» exclusivo en esta materia, como modo de atajar los más graves males de la república, anticipando con ello la posición de los llamados «arbitristas». ${ }^{6}$

Este trabajo aborda los usos que Juan Huarte de San Juan hizo de la Biblia en su Examen de ingenios para las ciencias (Baeza, 1575 y 1594). Tras un breve apunte de su formación, primero en Baeza como licenciado en artes y luego en Alcalá como doctor en medicina, se examina el recurso de Huarte al Pentateuco para reforzar su tesis - basada en la doctrina galénica de los temperamentos- sobre la excelencia natural de los judíos para la práctica de la medicina, y los rasgos de una llamativa espiritualidad paulina que instrumentaliza contra el proyecto de exclusión social de los cristianos nuevos, en línea con una tradición cristiana de pensamiento crítico muy viva en el mundo ibérico desde el siglo XV.

6 «Esto mesmo quisiera yo que hicieran las Academias [i.e., Universidades] de vuestros reinos [de Felipe II]; que pues no consienten que el estudiante pase a otra facultad no estando en la lengua latina perito, que tuvieran también examinadores para saber si el que quiere estudiar dialéctica, filosofía, medicina, teología o leyes tiene el ingenio que cada una de estas ciencias ha menester. Porque si no, fuera del daño que este tal hará después en la república usando su arte mal sabida, es lástima ver a un hombre trabajar y quebrarse la cabeza en cosa que es imposible salir con ella. Por no hacer hoy día esta diligencia, han destruido la cristiana religión los que no tenían ingenio para teología, y echan a perder la salud de los hombres los que son inhábiles para medicina, y la jurispericia no tiene la perfección que pudiera por no saber a qué potencia racional pertenece el uso y buena interpretación de las leyes» (EIC, 151-153). 


\section{ENTRE BAeza y Alcalá}

Durante las últimas décadas, se ha postulado una nueva clave para iluminar los no pocos aspectos oscuros de la biografía de Huarte y comprender mejor las motivaciones detrás del EIC, a saber, su vinculación, presumiblemente estrecha, al ambiente baezano contemporáneo. Como es bien sabido, durante las décadas intermedias del siglo XVI Baeza se caracterizó por una intensa fermentación espiritual a resultas de la "profusión de sensibilidades y actitudes religiosas innovadoras" a que contribuyeron de modo crucial tanto "alumbrados» como cristianos nuevos descendientes de familias judías convertidas al cristianismo (Sáez 2003, 39; Huerga 1978b, 1978c).

Huarte había nacido en la villa bajonavarra de San Juan del Pie del Puerto hacia 1529, pero su familia se trasladó a Andalucía en algún momento de la década de 1530, y se encontraba ya definitivamente establecida en Baeza antes de $1540 .^{7}$ En aquella época, esta ciudad contaba con unos 14.000 habitantes - que se convertirían en cerca de 26.000 en 1594- y atravesaba, como el resto del valle del Guadalquivir, una etapa de gran prosperidad económica (Carande 1965, 60). En 1538 se había establecido en ella un colegio de niños -el de la Santísima Trinidad - al que en 1542 se añadió un Colegio mayor con capacidad de otorgar grados universitarios (Ajo G. y Sáinz de Zúñiga 1957, II: 96-9; López Piñero 1979, 64; Huerga 1978a, 7-34). Artífice de esta transformación fue el sacerdote Juan de Ávila (1500-1569), destacado reformador eclesial de ascendencia judeoconversa, que quiso hacer del Colegio de Baeza la piedra angular de su reforma como universidad pastoral destinada a la formación del clero apostólico. La nueva universidad quedó facultada para conceder títulos de artes y teología en todos sus grados (bachiller, licenciado y doctor). En la búsqueda de un modelo inspirador para su facultad de teología, el «Apóstol de Andalucía» prefirió optar por Salamanca frente a Alcalá, por juzgar excesivo el modernismo complutense, en comparación con el «centrismo» teológico salmantino, entonces remozado a resultas de la competencia de Alcalá, y de la obra de Francisco de Vitoria y sus seguidores. En contraste con el modelo pluralista de estudios teológicos entonces de moda en el Colegio Trilingüe Complutense (específicamente dedicado al estudio de las lenguas latina, griega y hebrea), Juan de Ávila insistía en priorizar el estudio de la Sagrada Escritura y de la Summa Teologica de Tomás de Aquino (Huerga 1978a, 9-10).

Huarte debió de cursar sus estudios de primeras letras en el Colegio de la Santísima Trinidad. Posteriormente, cursó los de artes en la Universidad de Baeza, que culminarían con la obtención del grado de licenciado (Iriarte 1948, 28). Profesores suyos allí debieron de ser Hernando de Herrera ( $f$. 1549-1577) y Diego Pérez de Valdivia (1525-1589), dos clérigos estrechamente relacionados con Juan de Ávila, que en la década de 1570 serían acusados y procesados por el Santo Oficio como presuntos integrantes del grupo de «alumbrados» de Baeza-Úbeda (Huerga 1978a, 10, 75-84). ${ }^{8}$ Como bien

7 Aunque la merindad navarra de Ultrapuertos no fue incorporada de forma definitiva al reino de Francia hasta la Paz de los Pirineos (1660), había quedado militarmente desguarnecida por la Monarquía Hispánica desde 1530.

8 Diego Pérez pasó los últimos años de su vida en Barcelona donde fue profesor de teología de su Estudio General y fundó la Casa de Misericordia. Véase Sánchez Gómez 1949, 104-134; Giordano 2020. ha recordado Ricardo Sáez, el despertar intelectual de Huarte debió de quedar indeleblemente marcado por su formación baezana, conforme al programa educativo de Juan de Ávila. Este aspiraba a «erradicar la ignorancia fomentando una inclinación humanista hacia las ciencias profanas y sagradas en armoniosa consonancia unidas» como parte esencial de la reforma eclesial que propugnaba (Sáez 1989, 81-95). A todas luces, la influencia formativa del Colegio-Universidad de Baeza está en el origen del interés de Huarte por la selección de los «ingenios» más adecuados para el ejercicio de las distintas profesiones (Rincón González 2006, 40-145).

Ahora bien, más allá del influjo formativo de la universidad de Baeza en su interés por la selección de los ingenios más adecuados para las diferentes artes y ciencias, el naturalismo extremo que caracteriza el EIC de Huarte se encuentra en las antípodas de la indiferencia -característica del ambiente espiritual baezano- hacia el mundo natural y la visión providencialista de las relaciones entre los hombres y el mundo, de raíces agustinianas y que era común a erasmistas e iluministas. No es posible explicar este naturalismo sin tener en cuenta que en 1553, tras la conclusión de sus estudios de artes, el joven Huarte se trasladó a Alcalá de Henares para cursar los de medicina en la universidad complutense, donde en 1555 obtuvo el grado de bachiller, y en 1559, los de licenciado y doctor. Fundada en 1499 -merced a una bula pontificia otorgada por Alejandro $\mathrm{VI}$ - por el cardenal franciscano Francisco Ximénez de Cisneros (1436-1517) y abierta a los estudiantes en 1508, Alcalá era una universidad típicamente renacentista que, erigida bajo el patrocinio real, contaba con una organización centralizada y aristocrática. A diferencia de Salamanca y Valladolid, las otras dos grandes universidades castellanas del siglo XVI, Alcalá excluía expresamente de sus aulas la facultad de leyes y orientaba sus enseñanzas hacia la teología, la medicina y las artes. Parte esencial del proyecto de reforma eclesial impulsado por Cisneros y muy influida desde el principio por el movimiento humanista y, en particular, por los erasmistas, Alcalá, como otras universidades europeas contemporáneas, contó, desde 1528, con un "Colegio Trilingüe», convirtiéndose pronto en un destacado foco del humanismo cristiano europeo.

La facultad de medicina de Alcalá constituyó, junto a la de Valencia, el núcleo ibérico más notable del humanismo médico (Ajo G. y Sáinz de Zúñiga 1957-1979, I: 378-386; II: 291-308; Muñoyerro 1945; López Piñero 1979, 97-98). Este movimiento intelectual, vivo en Europa desde finales del siglo XV hasta su total agotamiento aproximadamente un siglo después, se caracterizó por la devoción a los textos médicos de la antigüedad clásica greco-latina, cuya recuperación a la luz de la naciente ciencia de la filología se planteaba como exigencia ineludible para el restablecimiento de las auténticas bases de la medicina europea; bases que, para los humanistas, se habían corrompido a resultas de la «barbarie medieval». Durante el segundo tercio del siglo XVI, Alcalá se convirtió en uno de los centros más dinámicos del humanismo médico europeo. Los estudios de Huarte en Alcalá, durante siete años, junto a destacados médicos helenistas marcaron profunda y decisivamente su pensamiento, haciendo de él un brillante heredero intelectual de su periodo de mayor esplendor.

De hecho, tanto su ostensible preocupación por el método en el estudio de la naturaleza como su naturalismo extremo tienen netas raíces complutenses. 


\section{LA BIBLIA EN EL EIC}

La presencia de la Sagrada Escritura en el EIC no pasa desapercibida al lector. Tal como se refleja en la Tabla (anexo), hemos podido contabilizar un total de 163 citas que se distribuyen de modo bastante equilibrado entre el Antiguo Testamento ( 86 citas, es decir, el $52,8 \%$ ) y el Nuevo ( 77 citas, es decir, el $47,2 \%)$. La práctica totalidad de las citas paleotestamentarias procede de los dos grupos conocidos como «libros históricos» (42 citas, 25, 8\%) - sobre todo el Génesis (15 citas, $9,2 \%$ ), el Éxodo (10 citas, 6,1\%) y el Libro de los Reyes (9 citas, $5,5 \%)-y$ «libros didácticos» (40 citas, $24,5 \%$ ). Entre las citas neotestamentarias, destacan las relativas a los evangelios (49 citas, 30,1\%), sobre todo Mateo (24 citas, 14,7\%), pero también Lucas (10 citas, $6,1 \%$ ), Juan ( 8 citas, $4,9 \%$ ) y Marcos ( 7 citas, $4,3 \%$ ); y las de las epístolas paulinas ( 24 citas, $14,7 \%$ ).

A efectos del tema que nos ocupa, estas últimas son de particular interés pues, como veremos, sugieren posibles afinidades de Huarte con la espiritualidad conversa. Por ello, nos centraremos en el uso de la Sagrada Escritura como fuente de autoridad, que Huarte hizo en su EIC, a través del ejemplo de las epístolas paulinas (EIC: 253-254, 258, 270, 317-319, 374, 426-429, 436, 449-452, 464, 514, 615, 716), no sin antes referirnos más brevemente a su recurso al Pentateuco para argumentar la excelencia de los judíos para la medicina práctica. ${ }^{9}$

\subsection{Los judíos y la medicina: el Pentateuco}

A juicio de Huarte, la «diferencia de imaginativa» más apropiada para la práctica de la medicina no abundaba en España, cuyos moradores poseían «buen entendimiento» y eran "prudentísimos», pero carecían "de memoria y de imaginativa», en virtud de la situación geográfica de la Península entre el "Septentrión» y la región «tórrida» (EIC, 414-417). Pese a considerar que el tipo de imaginativa propio de los habitantes por debajo del Septentrión era «tarda y remisa» y, por tanto, nada apropiada para la medicina, Huarte apuntaba a Egipto como la excepción a esta regla. Apelaba para ello, de un lado, al testimonio genérico de «los historiadores» para subrayar la destreza para la hechicería y el sentido práctico de "los gitanos» - cuyo origen acostumbraba a situarse en Egipto-; de otro, al juicio admirativo de Platón y Flavio Josefo (37/8-101) hacia los egipcios atribuyéndoles la invención de todas las ciencias pertenecientes a la imaginativa - «matemáticas, astrología, aritmética, perspectiva, judiciaria y otras así»- (EIC, 503-504).

Los judíos habrían adquirido su gran habilidad para la medicina práctica durante su dilatado cautiverio en Egipto - cuatrocientos treinta años, según el relato bíblico (Ex 12, 40) - y los cuarenta años de peregrinación por el desierto camino de la Tierra Prometida. En su extensa digresión sobre esta materia (EIC, 504-523), Huarte citó hasta trece pasajes bíblicos, entre ellos tan solo dos procedentes del Nuevo Testamento. ${ }^{10}$

\footnotetext{
9 Esta cuestión es abordada en extenso en el artículo de Arrizabalaga (2018, 405-426).

10 Las citas corresponden a: Génesis XV,13-14 (EIC, 507); Éxodo XII,40-41 (EIC, 508), XIII,21 (EIC, 515), XV,25 (EIC, 514), XVI,14 (EIC, 513), XVI,31 (EIC, 513), XVI,33-35 (dos veces) (EIC, 511), XVII,5-6 (EIC, 514); Números XI,6 (EIC, 514), XXI,5 (EIC, 522); Sabiduría XVI,20 (EIC,
}

La base argumental de su tesis gravitó sobre el impacto del cautiverio del pueblo judío en Egipto sobre su temperamento humoral, así como sobre sus costumbres seculares relativas a la ingesta de "aguas y manjares» que potenciaban la «diferencia de imaginativa» más propicia para la práctica de la medicina.

Huarte se aplicó con determinación a defender su tesis en clave galénica. Argüía que al «pueblo de Israel» se le habían pegado las "cualidades de Egipto» durante su largo y penoso cautiverio allí, porque la vida «en servidumbre, en tristeza, en aflicción y tierras ajenas» genera «mucha cólera requemada por no tener libertad de hablar ni vengarse de sus injurias», y este humor "tostado» constituye "el instrumento de la astucia, solercia y malicia». ${ }^{11}$

El ingenio del pueblo judío se había visto también afinado por las «calidades de Egipto y de las otras provincias» -muy afines entre sí- por donde anduvo en su largo peregrinaje por el desierto, pues las «regiones estériles y flacas, no paniegas ni abundosas en fructificar, crían hombres de ingenio muy agudo», en contraste con las «tierras gruesas y fértiles», que "engendran hombres membrudos, animosos y de muchas fuerzas corporales, pero muy torpes de ingenio». Para Huarte, el clima tórrido de esta región favorecía una clase de imaginativa caracterizada por la «astucia y solercia» de sus habitantes por volverles «el celebro tostado y la cólera requemada» (EIC, 508-511).

La tercera y última clave explicativa del «muy agudo» ingenio de los judíos para la medicina práctica radicaba, a juicio de Huarte, en los «manjares», las «aguas» y «la templanza» del aire del desierto por donde anduvieron a su salida de Egipto. Entre todos estos factores, prestó particular atención al maná, un producto similar a la «semilla de cilantro blanco" y de "sabor como de torta de trigo amasada con miel», que Dios había hecho caer del cielo para alimentarles, según el relato paleotestamentario (Ex 16, 14-36). Huarte lo identificaba con mel roscidum et aereum, un producto aparentemente conocido, semejante al rocío y que se generaba en el aire; y aunque admitía que la "sustancia» del maná era quizás "más delicada», y aceptaba el milagro divino de su caída del cielo, no por ello dejaba de considerarlo un alimento generado a través de causas naturales (EIC, 512).

A partir de la identificación del maná con mel roscidum et aereum, Huarte definía su «compostura» como «caliente y de partes sutiles y muy delicadas». Como no estaban acostumbrados a tal «delicadeza» porque sus «fuertes estómagos» estaban "hechos de ajos, cebollas y puerros», no lograban digerirlo y el maná se corrompía y acababa convirtiéndose en "cólera retostada» aguzadora de su ingenio. Lo mismo les sucedía al beber las "delicadas y sabrosas» aguas que Moisés hacía brotar de las piedras con su vara, acostumbrados como estaban a otras "gruesas y salobres». También aguzaba su ingenio el aire del desierto, que calificaba de "sutil y delicado» en virtud de la protección divina (EIC, 513-515).

Con este alimento, estas aguas y estos aires, los varones judíos habrían engendrado una «simiente» muy «delicada y

522); Hechos de los apóstoles VII,6 y 36 (EIC, 508), Pablo, Epístola 1a a los Corintios X,4 (EIC, 514).

11 «Solercia, astucia, solercia, versucia y malicia» (EIC, 517). 
tostada» y las hebreas, una "sangre menstrua» muy «sutil y delicada", de manera que "todos sus hijos y descendientes salieron agudos y de grande ingenio para las cosas de este siglo». Las numerosas penalidades - «trabajos, hambres, cercos de enemigos, sujeciones, servidumbres y malos tratos»- que el «pueblo de Israel» había sufrido con posterioridad a su llegada a su «tierra de promisión», continuaron asegurando el "temperamento caliente, seco y retostado» requerido para poseer ese «muy agudo ingenio» (EIC, 515-517).

Huarte, finalmente, sostenía que las «disposiciones de habilidad» adquiridas por la simiente de los judíos a partir «del maná, del agua, de los aires, de las aflicciones y los trabajos» de sus antepasados en Egipto durante más de cuatrocientos años, se habían conservado sin perderse en el transcurso de los dos mil años subsiguientes, incluso en España, una «región tan contraria a Egipto y donde han comido manjares diferentes y bebido aguas de no tan buen temperamento y sustancia como allí». Para explicarlo, hacía particular énfasis en las singulares virtudes del maná, un "manjar» extremadamente "delicado y sabroso» cuyas "calidades» habían impregnado "huesos, nervios y carne» de los judíos hasta tal punto que «por semejanza no apetecían ya otra cosa». Pese a admitir que los descendientes de aquellos judíos habían perdido en el transcurso del tiempo una parte de su agudo ingenio originario para la medicina práctica en razón de su dieta, su hábitat e incluso su mestizaje con los gentiles, a quienes negaba explícitamente la posesión de "esta diligencia de ingenio», Huarte subrayaba como innegable que el «pueblo de Israel» no había perdido del todo su singular ingenio para la medicina práctica. ${ }^{12}$

\subsection{La antropología del «nuevo nacimiento» [Ef 2,14-16]}

Hacia la mitad del EIC, Huarte cuenta una graciosa anécdota sobre el rey de Francia, Francisco I, que deseaba ser curado por médicos judíos y por ello pide al Emperador Carlos V que se le envíe uno desde España (Kimmel 2016, 336-356). Pero el que finalmente llega a Francia no es un médico judío sino converso. Antes de rechazarle, el soberano le pregunta si es verdaderamente cristiano, y al comprobar que así es, vuelve a pedir un médico judío, pero ya no a España, puesto que de allí solo podían llegar conversos. Este relato, probablemente inventado, sirve para presentar como una verdad asumida la visión de los hechos que quería transmitir Huarte: la medicina hispánica era una ciencia muy semitizada, y esto era un pasado que no se podía cambiar, sino solo aceptar; en cuanto al presente, los que practicaban esta ciencia eran únicamente médicos conversos que parecían haber dejado atrás su pasado hebreo. Si Huarte actuó en calidad de medicus politicus, como se ha recordado (Gracia Guillén 1983, 342-343), entonces su oficio fue

12 «Ello verdad es que no son ahora tan agudos y solertes como mil años atrás; porque desde que dejaron de comer maná lo han venido perdiendo sus descendientes poco a poco hasta ahora, por usar contrarios manjares, y estar en región diferente de Egipto, y no beber aguas tan delicadas como en el desierto; y por haberse mezclado con los que descienden de la gentilidad, los cuales carecen de esta diligencia de ingenio. Pero lo que no se les puede negar es que aún no lo han acabado de perder» (EIC, 523). el de proporcionar un sólido suelo de realismo sobre el que se tenía que levantar la acción política.

Bajo este mismo prisma de realismo político debe enfocarse su alabanza de la raza judía, ensalzada por su excelencia en el oficio de la medicina y, en general, por tener un tipo de ingenio privilegiado. Es muy interesante ver cómo Huarte argumenta su tesis: su explicación psicohistórica del ingenio de los judíos es una sublime prueba de empatía. El cautiverio en Egipto, los cuarenta años en el desierto, la «mala vida» sufrida por todas partes, la «continua tristeza y vejación» aseguraron durante siglos el temperamento requerido para tan agudo y peculiar «ingenio»; en otras palabras, el máximo sufrimiento se había traducido en agudeza y vitalidad. A su juicio, el pueblo judío rompía cualquier determinismo ambiental (desierto) y psicológico (desgarro): los judíos habían sido capaces de invertir el signo negativo inscrito en sus desafortunadas existencias. La experiencia de los cuarenta años en el desierto del pueblo judío y el hecho de haber sido alimentado con un manjar divino, delicado y exquisito como el maná, y las aguas que bebieron, determinaron su fisiología, en la que predomina la «cólera retostada». Cómo estas facultades siguieron preservándose en este pueblo, constituye un misterio incluso para él, pero lo cierto es que esos preciosísimos alimentos que llenaron los estómagos de los judíos durante los cuarenta años de desierto explican por qué "todos sus hijos y descendientes salieron agudos y de grande ingenio para las cosas de este siglo» (EIC, 515-516).

Con este brillante alegato biohistórico, Huarte logró que convivieran relato bíblico y galenismo: la directa intervención divina resguardó al pueblo elegido en las pruebas que éste consiguió superar. En definitiva, Huarte, con ese biologismo de raigambre galénica, cuestionaba otro biologismo, el que sustentaba la limpieza de sangre,,$^{13}$ levantado sobre la creencia en el carácter físico de la perversidad judaica (Sicroff 1960, 134). Cuando Huarte afirmaba que las cualidades de la sangre hebrea, a pesar del largo tiempo transcurrido, permanecían en este pueblo, daba la vuelta al argumento de la transmisibilidad por vía de sangre de la perversidad judaica: pues, si la «maldad judaica» permanece en la sangre, es lógico que también permanezcan sus cualidades. La conclusión que dejaba entrever a sus atentos lectores solo podía ser una: el mismo discurso biologicista y racial que excluía a los médicos conversos podía utilizarse para demostrar que eran los mejores del mundo.

Esta defensa de los judíos es una operación intelectual que, sin embargo, parece dejar algunos cabos sueltos. Cuando Huarte teoriza que el ingenio de los judíos era especialmente "agudo" y "grande para las cosas de este siglo», como la medicina práctica, en el fondo, ¿no sería ésta una manera de decir que la excelencia judía brilla más en una actividad práctica, como prácticas eran las actividades financieras y comerciales en las que era notorio que el ingenio judío siempre había destacado? Y, si así fuera, ¿no estaría respaldando un tópico del antisemitismo medieval, según el cual el judío era poco apto para la contemplación y muy versado en las actividades mundanas?

13 Gracia Guillén 1983, 328-352; Caro Baroja 1978, 2: 302; Méchoulan 1979, 126-129. 
No nos parece correcto extraer esta conclusión del pensamiento huartiano: el saber práctico y el teórico eran partes inherentes a la medicina universitaria de la época. La práctica médica no tenía un carácter meramente empírico sino que era una ars fundamentada en la filosofía natural: el médico, en la expresión de Tomás de Aquino, era un «artifex factivus sanitatis» (García Ballester 1995, 127-150).

En definitiva, Huarte no homenajeó el discurso bajomedieval, muy bien ilustrado en la cultura cristiana ibérica, que azotó a un judaísmo petrificado en el gesto observante (la letra mata de 2 Cor 3,6 ) y en el exangüe apego a la ley mosaica (Nirenberg 2012, 211-242). Según este discurso, que ha identificado lo judaico con la mundanidad y con el materialismo y el empirismo, el «compromiso con el mundo [...] podría imaginarse [...] como judaizante». ${ }^{14}$

Si Huarte hubiera respaldado esa percepción de lo judaico, rehén de un materialismo estéril, no podría alabar un linaje en cuya carnalidad, después de más de dos mil años, se custodiaba viva la fructífera herencia de los sufrimientos superados: con toda su autoridad de filósofo natural, daba fe de que, aunque pasaran tres mil años, el semen de Abraham no perdería las disposiciones en el ingenio que el maná le proporcionara. ${ }^{15}$

Tras alabar la raza judía por su excelencia en el ejercicio de la medicina, Huarte se convierte en el gran defensor de una antropología del "nuevo nacimiento», basada en el mérito y en las capacidades personales; consecuentemente, cualquier determinismo, tanto social como racial quedaba pulverizado: «No hay otra fortuna sino Dios y la buena diligencia del hombre» (EIC, 546). Lo que permanecía en pie del concepto de hidalguía lo liquida con la exquisitez sociológica del filósofo del lenguaje: si «hijodalgo» hace referencia a un "algo" heroico que un antepasado hubiera hecho y ese hecho de antaño no se confirma en el presente con una vida virtuosa o heroica, entonces «hijodalgo» querrá decir "hijo de nada». Este "algo», que funda la genealogía noble, se convierte en "nada» si no se produce un nuevo nacimiento, que simboliza el desprendimiento de los anteriores valores y una nueva apuesta por la práctica de las virtudes y el mérito del trabajo individual (EIC, 553-556). Con la sensibilidad de un ilustrado avant la lettre, presentía la inquietante raíz nihilista que se escondía en los cimientos de la sociedad del privilegio.

Además, si "hijodalgo» quiere decir "hijo de bienes», como confirma la Ley de Partidas, y estos bienes se entienden como bienes temporales, esta definición no funciona porque, argumenta Huarte, "hay infinitos hijosdalgo pobres, e infinitos ricos que no son hijosdalgo». Ahora bien, la definición funcionaría si en lugar de «bienes» pusiéramos "virtudes», pues en ese caso se habría dado un segundo nacimiento, de tipo espiritual, que haría al hombre «hijo de sus obras». Para fundamentar esta tesis, Huarte recuerda

14 "Our engagement with the world - indeed sense of perception itself - could be imagined within Christian culture as judaizing. [...] No pre-modern Western European society better illustrates this dynamic principle than Iberia» (Nirenberg 2012, 229).

15 EIC, 519. "Conforme a esta cuenta, bien pudo ser que en cuatrocientos y treinta años que estuvo el pueblo de Israel en Egipto, y cuarenta en el desierto y setenta en el captiverio de Babilonia, que fuesen menester más de tres mil años para que la simienta de Abrahán acabase de perder las disposiciones de ingenio que hizo el maná». el episodio de Cristo que reprende a Nicodemo "porque siendo doctor de la ley, no sabía que era necesario tornar el hombre a nacer de nuevo para tener otro mejor ser y otros padres más honrados que los naturales [Jn 3,4-10]» (EIC, 556).

De este «segundo nacimiento» (EIC, 550-560), transformador y catártico, procedían los self-made men cuyo éxito social no se debía ni al ciego azar, ni al privilegio de «ser bien nacido y de claro linaje», porque esta última condición "tiene una falta muy grande: que sola por sí es de muy poco provecho». Estos hombres nuevos eran conscientes del "valor de su persona» (EIC, 558): así lo expresaba Huarte a través de otro cuento, que inspiró a Cervantes un dialogo en su Persiles. Al final de una conversación entre un caballero y un capitán, el primero se dirige al segundo para preguntarle de quién era hijo, pues el capitán no aparentaba conocer a un hombre como él, con nobleza y antepasados. La respuesta no dejaba lugar a réplicas: «Señor, dijo el capitán, bien sé que vuestra señoría es muy caballero y que sus padres lo fueron también; pero yo y mi brazo derecho, a quien ahora reconozco por padre, somos mejores que vos y todo vuestro linaje» (EIC, 557-558).

El propio Huarte explica que la expresión «yo y mi brazo derecho a quien ahora reconozco por padre» aludía al "segundo nacimiento».

En consecuencia, proponía una nueva escala de valores: el primero de todos es el valor de la propia persona, seguido por el de su hacienda, y finalmente por el de la «nobleza y antigüedad de sus antepasados» (EIC, 559-560). Es evidente que en esta nueva jerarquía de las virtudes, la nobleza de sangre solo se quedaba en el tercer puesto y, en cuanto a la pureza del linaje, ni siquiera figuraba en su listado de valores.

Ser heraldo de esta antropología espiritual del hombre nuevo lanzó a Huarte al corazón del debate, muy vivo en su tiempo, sobre la inmovilidad o no de las clases sociales. Merece ser resaltado que para defender su opinión utilizara un argumento evangélico: las palabras de Jesús a Nicodemo sobre el nacimiento espiritual. ¿Por qué Huarte recurrió a este episodio del evangelio para sostener su visión meritocrática, habida cuenta de que su idea de sociedad, basada en el faber est suae quisque fortunae, hubiera podido defenderse igualmente con el galenismo del natura facit habilem? El argumento que elige Huarte, en cambio, el del nacimiento espiritual, estaba muy connotado y cargado de significados por ser un topos de la literatura conversa de los siglos XV (Cartagena, Oropesa, Talavera) ${ }^{16}$ y XVI (Juan de Ávila, Diego Pérez de Valdivia). ${ }^{17}$ Todos estos autores, junto con otros que no cabe aquí mencionar, defendieron la idea de que el «nacimiento espiritual» acontece en las aguas regeneradoras del bautismo, desde un punto de vista eclesiológico y, desde una vertiente espiritual, en el «alumbramiento» de la conversión.

En definitiva, Huarte utilizó un argumento evangélico, el más calificado, según su criterio, para apostar por la movilidad social y por una sociedad que, con un lenguaje actual,

16 Cartagena 1943, 146; Oropesa 1979, 653; para Talavera, véase Giordano 2018b, 94-110.

17 Cfr. Ávila 2001, I: 468 («por ser todos hijos de un padre del cielo que los tornó a engendrar otra vez por agua y Espíritu santo»); para Pérez de Valdivia, véase Giordano, en prensa. 
llamaríamos meritocrática. Indudablemente se trataba de un gesto engagé por parte de Huarte, que así incorporaba un concepto de origen paulino (luego sistematizado por Agustín de Hipona), como el de nuevo nacimiento espiritual (Ef 2,14-16; Col 2,12), al planteamiento educativo y antropológico de su obra.

Y, finalmente, observamos la perfecta naturalidad con la que Huarte enlazó su alabanza de la raza judía (en el discurso sobre la excelencia del ingenio de los judíos para la medicina), con la desvalorización del linaje, premisa de su visión meritocrática, y ello a pesar de la evidente incoherencia lógica entre los dos temas. Sin embargo, esta aporía - la alabanza del linaje que convive con su devaluación - tenía raíces profundas: formaba parte de la semántica del discurso religioso de Alonso de Cartagena en el siglo XV y de Juan de Ávila tras él. En estos autores, la primacía del linaje (el davídico $^{18}$ del que desciende Cristo) convive con su espiritualización (Cristo es el linaje, según Alonso de Cartagena, seguido por Juan de Ávila y Domingo de Valtanás $)^{19}$ para finalmente disolverse en un humanismo de méritos y virtudes.

A finales del siglo $\mathrm{XVI}$, este posicionamiento de Huarte anticipó la labor de servidores de la corona que, especialmente atentos a los problemas económicos que afligían a la monarquía endeudada de Felipe III, fueron capaces de ver las ventajas que se conseguirían mediante una aplicación menos rigorista de los Estatutos de limpieza de sangre y del Tribunal inquisitorial, no tanto reconfigurando el tema financiero, sino más bien ampliando las perspectivas de inserción social para los conversos en la vida del reino. ${ }^{20}$

18 En el Defensorium unitatis Christianae, Cartagena reitera este concepto, sintetizado en estas líneas: «Illi soli populo lata est ut quandam prerogativam sanctitatis preceteris obtineret propter reverentiam Christi qui nasciturus ex illo populo erat» (Cartagena 1943, 73). Trad.: «Solo a este pueblo [los judíos] la ley le fue ofrecida para que alcanzase ciertas prerrogativas de virtud por encima de los demás en atención a que de ese pueblo había que nacer Cristo» (Verdín Díaz 1992, 216); Juan de Ávila lo expresa ya en uno de sus primeros escritos importantes: «Y Cristo predicado es luz entonces y agora para los judíos que le quisieren creer: porque grande honra es para ellos venir de ellos, y principalmente a ellos, el que es Salvador de todo el mundo y verdadero Dios y hombre» (Las cursivas son del autor; Ávila 2001, I: 526).

19 Según Cartagena, Cristo es el nuevo David y en tanto que descendiente carnal de este gran rey bíblico ha hecho posible la «reducción» de dos linajes en uno: "Omnes homines in unam gentem reducti, neque ultra dicentur due gentes, sed una gens et unus populus sub uno rege et uno pastore, nominato David qui est Christus pastor bonus et rex regum filius David secundum carnem» (Alonso 1943, 139). Trad.: «Todos los hombres hemos sido reducidos a un solo linaje para que no se hable más de dos linajes, sino de uno solo y de un solo pueblo bajo un solo rey y bajo un solo pastor Ilamado David, que es el Cristo» (Verdín Díaz 1992, 198). Según Juan de Ávila, «Cristo es linaje, y por eso no se hace mención del linaje de la carne» (Ávila 2001, II, 121). Otra destacada figura, que se añade a quienes espiritualizaron el linaje, fue el dominico fray Domingo de Valtanás. He aquí sus palabras: «No hay otra nobleza cierta ni otro linaje de que nos devemos preciar sino de ser hijos de Dios por gracia (f. XXVII)" en su obra Doctrina Christiana (en casa de Martín de Montesdoca, Sevilla, 1555). Sobre las relaciones entre Juan de Ávila y Valtanás, véase Pastore (2003, 144-147). Sobre el linaje espiritual en Juan de Ávila, véase Fernández Cordero (2018, 113-133).

20 Revah 1971, 236-306; Gutiérrez Nieto 1990; Pulido Serrano 2006, 345-376. En 1622 un mercader cristiano nuevo portugués, Duarte Gomes Solis, envió un tratado a la corte regia en el que elaboraba «un nuevo concepto de nobleza, según criterios más meritocráticos y funcionales que biológicos» (Stuczynski 2014). Otra crítica a los estatutos de limpieza de sangre ha sido formulada por un jesuita,

\subsubsection{Pablo, el nuevo Isaías}

La espiritualidad paulina en el EIC se delinea como una afiliación intelectual a un "sentimiento vivo de la gracia» (Bataillon 1995, 167). Utilizada por Bataillon en el contexto del iluminismo toledano, esta expresión nos sorprende por su longevidad hermenéutica: mutatis mutandis esas palabras, a nuestro parecer, resumen el personalísimo enfoque que Huarte mantuvo en su interpretación de las Sagradas Escrituras. Como veremos a continuación, él aludió a la gracia en modo oblicuo, pero en pasajes significativos y con plena consciencia de toda la carga de problematicidad que conllevaba tratar un tema que parecía detener el extremado naturalismo de su pensamiento.

Volviendo, pues, a aquella sentencia tan usada de los filósofos antiguos, Natura facit habilem, es de entender que hay ingenios y habilidades que Dios reparte entre los hombres fuera del orden natural, como fue la sabiduría de los apóstoles, los cuales, siendo rudos y torpes, fueron alumbrados milagrosamente y llenos de ciencia y de saber. De este género de habilidad y sabiduría no se puede verificar Natura facit habilem; porque ésta es obra que inmediatamente se ha de reducir a Dios, y no a Naturaleza. Lo mesmo se entiende de la sabiduría de los profetas y de todos aquellos a quien Dios infundió alguna gracia (EIC, 242).

Como Huarte admite, frente al poder transformador de la gracia divina, un poder al alcance de cualquiera a quien Dios decidiera otorgarlo, la sentencia de los antiguos, Natura facit habilem queda suspendida: "hay ingenios y habilidades que Dios reparte entre los hombres fuera del orden natural», como hizo con los Apóstoles, hombres "rudos y torpes» que fueron «alumbrados milagrosamente y llenos de ciencia y saber».

Sin embargo, todo lo que Huarte añadió a continuación, hasta el final de capítulo IV, daba a entender que el milagro del "alumbramiento" por medio de la gracia era algo extraordinario por parte de Dios, aunque los hombres hubieran deseado una gracia más bien ordinaria, porque, puntualiza Huarte, eran impacientes y vagos, y querían que sus deseos se cumpliesen en el acto, sin esperar o trabajar por ello. Con esta aclaración posterior, Huarte blinda la que podía interpretarse como una sospechosa apuesta «radical» en favor de la gracia y de sus efectos en los hombres, «alumbrados milagrosamente», como ocurrió a los apóstoles. En definitiva, subrayar el carácter extraordinario de la gracia fue quizás una medida prudencial para asegurar que este concepto se utilizaría siempre con aquella «moderación» que Ignacio de Loyola recomendaba a sus discípulos. ${ }^{21}$

La precaución de Huarte al abordar este tema se entiende mejor si se detallan algunos datos relacionados respectivamente con el contexto teológico, espiritual y literario.

Fernando de Valdés, rector del noviciado de la Compañía de Jesús en Madrid y calificador del Consejo supremo de la Inquisición: en 1632 publicó un memorial en el que defendía la abrogación de esos estatutos (Hernández Franco, Ortega del Cerro 2014, 22-37). Otro caso, muy interesante, hace referencia a un servidor de la corona, autor de una propuesta de reforma de los Estatutos de limpieza de sangre (c.1625) en la que menciona a san Pablo (Hernández Franco 2014, 477-491).

21 El mismo Ignacio de Loyola (1952, 238), como recuerda Quilliet (2007), había sugerido en los ejercicios usar la gracia «con moderación». 
Entre finales del siglo XVI y principios del XVII, se desencadenó la contienda de auxiliis divinae gratiae: este debate teológico, el más encendido del siglo, sin duda, tuvo como objeto el rol de la gracia en la salvación del hombre. En él se enfrentaron jesuitas y dominicos, cada cual defendiendo sus posturas. Los primeros exaltaban el papel salvífico de las obras, mantenidas al mismo nivel que la gracia. Los dominicos, en cambio, fieles al legado de la tradición católica de la que se consideraban los defensores, destacaban el papel de la gracia, aun sin restar importancia a las buenas obras en la salvación del hombre. Esta disputa teológica tuvo infinidad de matices y sutilezas imposibles de resumir aquí, aunque debe recordarse que todas ellas elevaron la temperatura del enfrentamiento teológico en el ajetreado último cuarto del siglo XVI (Beltrán de Heredia 1968).

Otro dato a tener en cuenta lo proporciona el contexto espiritual. La gracia era un concepto adscrito a un universo espiritual sospechoso -la expresión de Bataillon antes mencionada da fe de ello-, una razón más que suficiente para emplear un cuidado exquisito si verdaderamente no podía eludirse su mención. Más allá de la controversia teológica del debate de auxiliis - chispeante polémica y legítimo reajuste de cuentas dentro de la Iglesia católica-, la sobrecarga ideológica que conllevaba el tema de la gracia procedía de una quiebra en el subsuelo espiritual del cristianismo hispano: según cómo se manejara ese concepto, podían deducirse los parámetros individuales que determinaban la pertenencia a una u otra forma de vivir la fe (Quilliet 2007).

Cabe añadir, por último, que la gracia contaba con buenas credenciales literarias como argumento en favor de la causa conversa. ${ }^{22}$ En este sentido la utilizó Mateo Alemán, en su célebre obra Guzmán de Alfarache, publicada en Madrid en $1599 .{ }^{23}$ El autor relata la vida de un pícaro, convertido en prototipo literario de esa tipología humana, que se plantea cambiar el rumbo de su vida y empezar a servir a Dios: así él demostraría merecer («comprar») la gracia cuyo "precio» había sido pagado a través de "los méritos de Cristo». De paso, cabe observar lo sorprendente que resulta ver a un pícaro manejar con semejante soltura conceptos teológicos tan hondos. De todas formas, el mensaje de Mateo Alemán era claro: si todos los cristianos, según el Tridentinum, mediante un acto de la voluntad que consistía en aceptar la gracia, podían imprimir un cambio a sus vidas y orientarlas hacia Dios, entonces a todos les estaban garantizadas las mismas posibilidades de salvación. Por lo tanto,

22 El tema de la gracia aparece significativamente en un escrito que un autor anónimo envió al Conde-duque de Olivares. En este documento se desmantelaban las justificaciones teológicas de la limpieza de sangre. Véase al respecto el estudio de Irigoyen López 2010, 154-156.

${ }^{23}$ Guzmán de Alfarache hablando una noche consigo mismo, llegaba a este profundo grado de introspección: «Esos trabajos, eso que padeces, y cuidado que tomas en servir a ese tu amo, ponlo a la cuenta de Dios [...]. Con eso puedes comprar la gracia, que, si antes no tenía precio, pues los méritos de los santos, todos, no acaudalaron con qué poderla comprar, hasta juntarlos con los de Cristo, y para ello se hizo hermano nuestro, ¿cuál hermano desamparó a su buen hermano? Sírvelo con un suspiro, con una lágrima, un dolor de corazón, pensándote de haberle ofendido. Que, dándoselo a él, juntarás tu caudal con el suyo, y haciéndolo de infinito precio, gozarás de vida eterna (la cursiva es nuestra)» (Alemán 1987, 2/III, 8, 505-505). hasta un pícaro podía tener un gran dominio de la teología cristiana (Bjornson 1973, 325-327).

En definitiva, la gracia no podía ser un asunto «neutro», no solo por la obvia repercusión del cisma luterano, sino también por tratarse de un pilar de la espiritualidad interior. En efecto, este "sentimiento vivo de la gracia», antes mencionado, fue uno de los rasgos sobresalientes de toda una corriente de espiritualidad que, desde las primeras décadas del siglo XVI, fue asimilada a una fenomenología heterodoxa y en no pocos casos identificada como expresión de herejía. Como es bien sabido, el elemento converso tuvo un papel destacado en ella (Pastore 2003, 2004); lo prueban los procesos inquisitoriales en contra de iluminados/alumbrados y erasmistas.

Todas estas fuentes documentan el protagonismo innegable de la figura de Pablo (Giordano 2004 y 2014, 49-70), desde el siglo $\mathrm{XV}$ rescatado por letrados y obispos conversos: muchos judíos, desde finales de la Edad Media, se convirtieron al catolicismo cautivados por el carisma de quien había sido apodado, _iironía de la historia!- «el apóstol de los gentiles» (Giordano 2018a, 226-251). Como veremos, Pablo ocupa, también en el EIC de Huarte, un lugar destacado. Todo relato de conversión supone un reto a la hora de historiar el dinamismo interior que lo prepara, aunque es objetivable en la transformación visible de las personas y de sus vidas. Las conversiones masivas ya habían ocurrido unas generaciones antes, en el transcurso de más de un siglo a partir de finales del XIV, pero de ese terremoto social y existencial quedaba todavía intacta - y las páginas de Huarte así nos la devuelven-, la fascinación por la figura del Apóstol. De él se valoraba el pasado judío y su identidad sincrética (judío de sangre, romano de ciudadanía y griego de educación), pero sobre todo su decisiva apuesta por la cohesión teológica y espiritual entre el mundo judío y el legado de Cristo.

Al igual que muchas destacadas figuras del siglo XVI —Juan de Valdés, María de Cazalla (Giordano 2014, 49-70), Bartolomé de Carranza (Giordano 2018c, 127-143), Domingo de Valtanás (Pastore 2003, 145), Juan de Ávila (Giordano 2010, 43-91), fray Luis de Granada (Kaplan 2019, 81-99) Diego Pérez de Valdivia (Giordano 2020, 33-106)-, también Huarte fue sensible a esta admiración intelectual despertada por Pablo. Quizás por ello lo menciona en el capítulo IX entre los hombres de "gran entendimiento» que no recurren al arte oratoria para convencer. Entre los judíos - precisa - había desconfianza hacia toda persona que hablase con "ornamento y policía», considerada engañosa y embaucadora (Mondejar 1984, 83). Precisamente esta falta de habilidad en el arte oratoria, que el mismo Pablo reconoció como su propio estilo - «Yo bien confieso que no sé hablar»-, lo hizo más creíble ante los lectores de Huarte:

El ingenio de san Pablo era apropiado para este ministerio; porque tenía grande entendimiento para defender y probar, en las sinagogas y en la gentilidad, que Jesucristo era el Mesías prometido en la ley, y que no había que esperar otro ninguno. Y, con esto era de poca memoria; por donde no pudo saber hablar con ornamento de palabras dulces y sabrosas. $Y$ esto era lo que la publicación del Evangelio había menester (EIC, 427). 
En estas líneas, Huarte no se limita a alabar el ingenio de "san Pablo» como evangelizador; recupera también la faceta judía del "apóstol de los gentiles», incansable predicador en las sinagogas, en las que decía que no había que esperar a otro Mesías. Todos estos matices apuntaban evidentemente a un manejo de la figura de Pablo desde la vertiente judeoconversa.

Huarte sitúa a «san Pablo» en la galería de insignes pensadores del pasado, médicos y filósofos griegos, Aristóteles, Platón e Hipócrates y Galeno, cuyos escritos se intercalan en su obra. Su figura sobresale por autoridad, entendimiento, carisma —ingenio ... apropiado para este ministerio»-, credibilidad (por no ser un buen orador), «dones sobrenaturales» (por la «gracia y auxilio que Dios para ello le dio»), e infalibilidad en su doctrina, pues «el Espíritu santo presidía en él ... para que no pudiese errar» (EIC, 427-429).

La pluma de Huarte regala a sus lectores la imagen de un «ingenio» extraordinario; después de Jesucristo, es el único representante del mundo cristiano al que dedicó una alabanza tan bien argumentada y rotunda. El Pablo de Huarte solo se codeaba con un rey bíblico, David, y parece haber superado en importancia a todos los profetas del Antiguo Testamento. Su autoridad estaba tan acrecentada que llegaba a cubrir un llamativo vacío de autores cristianos en el EIC. El Apóstol era, en definitiva, el destinatario de un verdadero don de profecía: esa «habilidad» no natural, sino divina, con la que Dios «quiso fabricar un hombre en el vientre de su madre» para que pudiera «descubrir al mundo la venida de su Hijo» (Gal 1,15-16) ${ }^{24}$ y para que "tuviese talento para probar y persuadir que Cristo era el Mesías prometido en la ley» y «no había que esperar otro ninguno» (EIC, 427).

Huarte aprovecha el topos renacentista sobre la crítica al clero ignorante y negligente para desatar una invectiva contra los que llama, en sintonía con la vis paulina, "discípulos del diablo» (EIC, 453)..$^{25}$ No podemos evitar el paralelismo con otro arrebato, el de Juan de Ávila que, acudiendo a la misma fuente paulina, los tildó de «falsos Cristos» (Ávila 2001, II: 31). ${ }^{26}$ Huarte les reprochaba que no practicasen la caridad que enseñó el Apóstol ("Charitas de corde puro», $1 \operatorname{Tim} 1,5)$, que no tuvieran ni buena consciencia, ni fe auténtica. Y con palpable ironía alude a unos «legis doctores» que no entienden de lo que hablan ni lo que afirman [1Tim 1,7$]^{27}$ (EIC, 450) y cuya única finalidad era "adquirir algo para sí» (EIC, 453).

24 EIC, 463. Encontramos la misma cita de Gal 1,15-16 en Juan de Ávila 2001, II: 189.

25 Huarte cita y a continuación ofrece a sus lectores una traducción de dos fragmentos, ensamblados por él, de la segunda carta de san Pablo a los Corintios (2Cor 11, 3,13-15): "Mucho me temo, hermanos míos, que así como la serpiente engañó a Eva con su astucia y maña, no os trastornen vuestro juicio y sentido [...] porque estos falsos apóstoles son como caldo de zorra, predicadores que hablan debajo de engaño; representan muy bien una santidad, parecen apóstoles de Jesucristo y son discípulos del diablo». La cursiva es nuestra (EIC, 453).

26 "“Falsos Cristos" quiere decir que vendrán hombres, los cuales no solamente representarán tanta santidad como san Pablo o los Apóstoles, sino como el mesmo Jesucristo; y que con representar tanta santidad y hacer tantos milagros, dice que no los habemos de creer; porque debajo de esa grande apariencia de santidad y milagros viene encerrado el demonio y el Anticristo. Pues ¿a quién habemos de creer? A lo que [Él] dijo». Ávila 2001, II: 31

27 «Non intelligentes nec quae loquuntur nec de quibus affirmant» $(E I C, 450)$.
Ávila usó las mismas citas -la de Mateo 15,14 y los versículos de la primera epístola de Pablo a Timoteo (EIC, 450) - para estructurar una vigorosa reprimenda a los «negligentes pastores» en su Memorial Segundo al Concilio de Trento. ${ }^{28}$

Como el propio testimonio de Pablo confirma, el concepto de caridad y el de cuerpo místico perseguían una ratio unitiva e implicaban una evangelización ininterrumpida, rasgos que no parecen destacar en una institución con la configuración y características del Santo Oficio. ${ }^{29}$ Sin embargo, no eran tiempos para ejercer "actos de desobediencia». Tras una reverencia formal al Tribunal inquisitorial, Huarte no citó ni un solo autor católico, excepto Pablo, y fugazmente, Cayetano, el famoso cardenal tomista que tuvo un coloquio con Lutero. ${ }^{30}$ Brillan por su ausencia los padres de la Iglesia y los pensadores cristianos. ${ }^{31}$ En su altiva soledad, el apóstol Pablo llena todo el espacio de lo sobrenatural, junto con la desnudez del texto bíblico, único y solitario contrapeso al pensamiento de los filósofos y médicos griegos.

3.2.2 «La letra mata, mas el Espíritu da vida [2Cor 3,6]»: la hermenéutica bíblica según Huarte

En el capítulo XI del EIC, Huarte, aprovechando una disquisición sobre el uso del término "letrado», afirma lo siguiente: "Los teólogos no se pueden llamar letrados (en esta significación) porque en la divina Escritura littera occidit, spiritus autem vivificat [2Cor 3,6]». E inmediatamente añade que la divina Escritura es «muy misteriosa, llena de figuras y cifras, oscura y no patente para todos». Incluso, puntualiza, quienes conocen los tres vulgares trilingües (latín, griego y hebreo), no llegan a atrapar la significación que tienen sus «vocablos y maneras de hablar». De modo que, concluye, el teólogo que «construyere la letra y tomare el sentido que resulta de la construcción gramatical, caerá en muchos errores» (EIC, 468-469). En otras palabras, quienes escudriñan las Escrituras «van perdidos». Las razones de ello ya las había expresado unas páginas atrás:

Porque los vocablos del texto divino y sus maneras de hablar tienen muchas otras significaciones fuera de

28 Ávila 2001, II: 524-534. El Memorial segundo al Concilio de Trento (1561) se publicó por primera vez en las Ediciones de la BAC en 1970-71, en las Obras completas editadas por Luis Sala Balust y Francisco Martín Hernández.

29 Con esta forma mentis Pablo se enfrentó al problema de defender las comunidades de los primeros cristianos de los «malos influjos», en otras palabras, las desviaciones que amenazaron la unidad de esos grupos de neoconvertidos.

30 Tommaso de Vio (1469-1543), también conocido como el "cardenal Cayetano", fue teólogo, maestro general de los dominicos y diplomático de la Santa Sede. Tomista renombrado, escribió numerosos comentarios de la Summa. Entre sus iniciativas, destaca una traducción de la Biblia que llevó a cabo con la ayuda de unos rabinos y que hizo para contrarrestar las tendencias humanísticas. Fue autor, entre sus muchos escritos, de las Epistolae Pauli et aliorum Apostolorum ad Graecam veritatem castigatae, 1571, París, Editorial apud Hieronymum de Marnef [et] Guillielmum Cauellat, sub Pelicano Monte D. Hilarij. Su nombre aparece también en los escritos de Juan de Ávila y Domingo de Valtanás.

31 Este vacío tal vez fue debido a su «velado» desacuerdo con la teología positiva, basada en los comentarios de los padres de la Iglesia, proclamados con la elocuencia de las bonae litterae. Cfr. Rincón González 2006, 142. 
las que supo Cicerón en latín; lo otro, que a los tales les falta el entendimiento, que es la potencia que averigua si un espíritu es católico o depravado. Ésta es la que puede elegir (con la gracia sobrenatural), de dos o tres sentidos que salen de una letra, el que es más verdadero y católico (EIC, 430).

Según anota Serés, Huarte polemiza veladamente con los teólogos de la Reforma, reconocibles por su apego a la letra, una actitud muy propia del estilo humanístico; así, el «recalcitrante» filosofo natural se disociaría de la hermenéutica humanística para aproximarse a la tomista (EIC, 469). . $^{32}$

Compartimos la observación de este estudioso, pero creemos necesario hacer emerger otros elementos de análisis. Huarte consideraba que el estudio filológico de la Biblia no estaba habilitado para esgrimir su verdadero significado y por esta razón no toleraba la omnipotencia interpretativa del método humanístico y la invasiva intermediación de sus teólogos o, tal vez, de los teólogos en un sentido general. Con un gesto contracorriente, análogo al que antes le había llevado a menospreciar la elocuencia de los predicadores, volvió a situar las Escrituras en una dimensión mistérica, personal, irreductible a cualquier tipo de categorización filológico-humanística y, por ello citó a continuación el versículo paulino de 2Cor 3,6. Era un anclaje correcto, porque tras la crítica al método hermenéutico humanístico se asomaba un radicalismo entonces indefendible - la resonancia interior de la palabra divina como dimensión hermenéutica-, en el que actuaba «la gracia sobrenatural» (EIC, 430). Para que se encienda esta dimensión era insuficiente la inmersión del filólogo, era necesario el "Espíritu» del que habla Pablo en el citado versículo; $y$, por supuesto, todo ello era impensable sin una relación personal $-\mathrm{y}$ no mediada - con la Escritura.

Los escritos paulinos se prestaban a este tipo de interpretación espiritual, precisamente porque en ellos el sentido literal "coincide con el Espíritu» y «se revela por iluminación»; ${ }^{33}$ en otras palabras, la propia experiencia de Pablo (un hombre a quien le fue revelado el sentido de la letra) fue elevada a metodología exegética por quienes, como Huarte, defendieron esta lectura de 2Cor 3:6.

Observamos que el «recalcitrante Huarte», en otro fragmento de su obra, defiende pacíficamente la interpretación literal de las Escrituras. ${ }^{34}$ No tenemos ningún elemento para sospechar que el apego al sentido literal de las Escrituras pudiera alterar la relación iniciática con una palabra «misteriosa, llena de figuras y cifras» (EIC, 469). Como Huarte sabía muy bien, fray Luis de León demostró con sus obras que la fidelidad a la literalidad podría engendrar una hermenéutica creadora de poesía y rebosante de espiritualidad.

Podemos concluir que en Huarte la visión paulina constituye el fulcro y el motivo inspirador de una exegesis cristiana. De ella hemos aislado dos características: en primer

32 Según la hermenéutica tomista, solo los escolásticos pueden hacer una acertada exegesis de la Biblia y, en una interpretación más estricta del tomismo, solo Dios, siendo su autor, es el único conocedor de las Escrituras.

33 Cessi 1957, 25.

34 «De muchos sentidos católicos que la Escritura divina puede recibir, yo siempre tengo por mejor el que mete la letra que el que quita a los términos y vocablos su natural significación» (EIC, 682). Como explica Serés, aquí «meter» quiere decir "tener en cuenta, seguir». lugar, su autonomía respecto a la tradición humanística. En segundo lugar, el estilo hermenéutico paulino, defendido por Huarte de San Juan, acoge el sentido espiritual de las Escrituras respetando el sentido literal. A este propósito, nos parece oportuno recordar un dato general, útil para ofrecer una visión más global y, tal vez, una mayor definición de la posición huartiana: ni el paulinismo europeo pre luterano, ${ }^{35}$ ni el paulinismo pro converso hispánico del siglo XV, asumen el sentido literal y el sentido espiritual de las Escrituras en una óptica de mutua contraposición. ${ }^{36}$

No forma parte de los objetivos de este estudio explorar la deuda que Huarte pudo tener con estos paulinismos, en particular con el segundo, pero es importante aclarar que su ataque a la hermenéutica humanística de las Escrituras y al cristiano cultivo de las bonae litterae no implicó un ataque al sentido literal.

Esta conclusión trasciende el ámbito de la exegesis bíblica, porque sobre los dos términos de la diada letra/ espíritu se fueron depositando a lo largo del siglo XVI significados socio-religiosos (Morreale 1986, 417-427): una tensión irresuelta entre estos dos polos agitó y marcó a fuego las vivencias religiosas más abiertas a una implicación personal del creyente, elemento indispensable para encender el combate letra/espíritu.

Es posible imaginar los ecos levantados por 2Cor 3,6 -manifiesto espiritual de un cristianismo paulino condenado (Giordano 2014, 49-70) - entre los lectores de Huarte y las conexiones con ámbitos o circuitos culturales y religiosos familiarizados con esas palabras del Apóstol. Obviamente, no tendría sentido insinuar una afinidad de Huarte con el castigadísimo iluminismo toledano, temporalmente distante, y ya completamente desmantelado por el Santo Oficio y sepultado bajo la espesa capa de una perseverante damnatio memoriae. Sin embargo, esa cita paulina, y las muchas otras referencias bíblicas que encontramos en el tratado de Huarte, traban un discurso religioso en el cual le démon de la espiritualidad interior seguía con vida, pese a todo.

\section{CONSIDERACIONES FINALES}

Algunos estudiosos han atribuido a Juan Huarte de San Juan un linaje judeoconverso (Gracia Guillén 1984, 344). Como ya se mostrado en otra ocasión (Arrizabalaga 2018, 553$, n. $81 ; 563$, n. 108$)$, se trata de una hipótesis totalmente descartable no solo por cuanto sabemos acerca

35 El paulinismo preluterano conoció una época muy florida en las universidades de Oxford y París en la segunda mitad del siglo XV. En Oxford, en particular, gracias a las enseñanzas de John Colet, su máximo inspirador, y futuro maestro de Erasmo, esta corriente consiguió abrir perspectivas de reformas eclesiásticas, orientadas hacia una renovación integral y profunda del pensamiento religioso, poniendo como «premisa insustituible» la interpretación espiritual de las Escrituras. El cultivo de esta última no implicaría desatender el sentido literal, sino todo lo contrario (Cessi 1957, 3-30).

36 El paulinismo de Huarte podía tener una deuda directa con un paulinismo hispánico anterior, un estilo exegético florecido en la segunda mitad del siglo XV español. Esta modalidad hermenéutica, esencialmente favorable a la causa conversa, fue promovida por distinguidos prelados como Cartagena, Oropesa y Talavera, que adoptaron el sentido espiritual de las Escrituras en asociación con el literal (Stuczynski 2012, 151-176). 
de sus orígenes familiares, sino también por su autoidentificación profesional con los filósofos naturales, y no con los médicos prácticos. Sin embargo, ello no fue óbice para que Huarte diera muestras de inequívoca simpatía hacia los judíos, tanto cuando elogiaba su ingenio, a su juicio singularmente agudo, para el ejercicio práctico de la medicina, como cuando criticaba las normas de acceso a las principales facultades de medicina castellanas, donde entonces se primaba una pretendida nobleza de sangre - recuérdese la plena vigencia de los estatutos de limpieza de sangre en ese periodo- en detrimento de la minoría judeoconversa (Peset 2000). Esta circunstancia, junto a la defensa, en una obra centrada en la selección de los mejores ingenios profesionales al servicio del imperio, de la idea de que toda nobleza tenía su origen en la valía personal, dejaba el camino de la formación médica universitaria potencialmente expedito a esta minoría; la cual, a juicio de Huarte, atesoraba no poca de la privilegiada habilidad natural para el ejercicio médico, que los judíos habían adquirido durante su largo cautiverio en Egipto y sus años de errancia por el desierto en busca de la Tierra Prometida. Todo ello en contra del proyecto de exclusión social de los cristianos nuevos sobre el que gravitaba la Monarquía Hispánica.

Huarte encontró en las Escrituras una herramienta formidable para cuestionar esta exclusión. En este sentido, fue un precursor de la corriente de opinión compuesta por clérigos y observadores económicos y servidores de la corona que, desde finales de la centuria, pidió una suavización de los estatutos de limpieza para facilitar la inserción social de los conversos. La discriminación empezaba a verse como una de las causas de la decadencia económica que azotó al imperio español en el siglo XVII.

El uso que Huarte de San Juan hizo de las Escrituras no se limitó solo a esta función político-social: la visión paulina, que desglosó en una teología de la caridad y del hombre interior, le hizo consciente de los límites de la hermenéutica humanística de las Escrituras.

La relación con Juan de Ávila, para este hijo adoptivo que fue Huarte de Baeza, ciudad en la que cursó sus primeros estudios y en la que fueron publicadas la editio princeps (1575) y la subprinceps (1594) de su obra, podría contribuir a aclarar el origen de la preminencia espiritual otorgada a Pablo. El paulinismo de Huarte deja de sorprender si contextualizamos su obra en el clima intelectual baezano en el que se formó. El contacto con el paulinismo de Juan de Ávila ${ }^{37}$ es mucho más que una sospecha: Huarte pudo haberle conocido directamente en los años en los que cursó los estudios de primeras letras en el colegio de la Santísima Trinidad, dirigido por este gran reformador eclesial. De esta ósmosis de ideas e influencias recíprocas es prueba una obra de Diego Pérez de Valdivia, alumno, profesor y posteriormente rector de la universidad de Baeza, cargo que ocupó por última vez en 1574. Este sacerdote, hijo espiritual de Juan de Ávila, biblista y escritor místico, utilizó con soltura conocimientos médicos que desvelan su familiaridad con la fuente huartiana en una obra suya, De sacra ratione concionandi, publicada por primera vez en Barcelona en 1583 (Pérez Aguilera 2005, 119-135).

37 Bataillon 1955, 5-44; Márquez Villanueva 2000, 77-98; García Villoslada 1970, 615-646.
Dicho eso, es más que lícito preguntarse cómo esta religiosidad paulina pudo coexistir con el «extremado naturalismo corporalista» (Arrizabalaga 2020, 584) del autor de EIC. Contestar a este interrogante requeriría un estudio $a d$ hoc. Aun así sería desacertado reducir la impronta paulina de la espiritualidad huartiana a una táctica compensatoria adoptada para cubrir con una capa de ortodoxia cristiana el radicalismo naturalista de sus creencias en campo médico. Si hubiera sido así, el remedio habría sido peor que la enfermedad, puesto que su afiliación paulina bajo ningún concepto se podía considerar una opción menos arriesgada que su extremado naturalismo.

En el EIC Huarte somete la categoría del linaje a un inteligente escrutinio intelectual con la finalidad de deconstruirla: categoría demolida, en tanto que causa de exclusión social, pero ensalzada como linaje davídico y reivindicada como orgullosa herencia carnal, puesto que proporcionó un argumento, bíblicamente fundamentado, para defender la aptitud del pueblo judío en el ejercicio de la medicina. Compartimos con Rafael Mandressi $(2016,59-87)$ la opinión de que esta defensa de Huarte de la excelencia de los judíos en la práctica de la medicina entraña «un significativo y robusto gesto político».

Queda una zona oscura en la biografía de Huarte. Fue contratado como médico de Sigüenza hacia finales de 1575 y en la misma ciudad se instaló en enero de 1576 para asumir la cátedra de medicina en el Colegio Universidad de San Antonio de Porta Coeli. Sin embargo, pronto optó por la sombra y se desvinculó de ambos oficios: en septiembre de ese año, el Consejo de Sigüenza revocó su contrato y en noviembre las actas de la universidad prueban que ya había dejado la ciudad (Mandressi 2016, 68). Se estableció en Linares, cerca de Baeza, y allí falleció en 1588. Cabe preguntarse por qué se sintió más libre desprendiéndose de estas profesiones, ambas expuestas a una fuerte visibilidad social y de las que acabó huyendo insatisfecho o sumamente incómodo (Peset Reig 2000), para finalmente entregarse al solitario retiro del filósofo natural. Su inconstancia profesional, y el alejamiento "de la capilla, de la intriga y de la actividad universitaria» (Mondejar 1984, 86), desembocaron en la enorme fortuna editorial de su obra, que lo consagró como el autor de uno de los tratados más influyentes de la Monarquía Hispánica, también por su extraordinaria proyección internacional. La renuncia a una visibilidad profesional fue compensada por una libertad de expresión que, para esos tiempos, fue realmente increíble.

Si la figura de Huarte guarda encerrado el misterio de su propia historia personal, pese a ello (o quizás igracias a ello!) ha podido revelar al mundo un proyecto educativo absolutamente rompedor, resultado de una atrevida fusión entre una antropología meritocrática, de raigambre galénica, y el pensamiento paulino. ${ }^{38}$

38 Compartimos la acertada conclusión de Guido Giglioni, según la cual Huarte formó parte de una elite intelectual que aceptó jugar "this riskiest of games all the way through. This was no longer playing with the idea of a double truth (by simulating or dissimulating); this was playing with the idea that one truth, when it was presented as sufficiently inclusive, could unite rather than divide minds» (Giglioni 2018, 134). 


\section{FUENTE}

Alemán, Mateo. 1987. Guzmán de Alfarache. Edición de José María Micó. 2 vols. Madrid: Cátedra.

Ávila, Juan de. 2001-2007. Obras completas. 4 vols. Madrid: BAC.

Ávila, Juan de. 1970-1971. Obras completas del santo maestro Juan de Ávila. Introducción, edición y notas de Luis Sala Balust, nueva edición revisada por Francisco Martín Hernández. Madrid: BAC.

Cartagena, Alonso de. 1943. Defensorium unitatis Christianae, edición de Manuel Alonso. Madrid: CSIC.

De Vio, Tommaso. 1571. Epistolae Pauli et aliorum Apostolorum ad Graecam veritatem castigatae. París: Editorial apud Hieronymum de Marnef [et] Guillielmum Cauellat, sub Pelicano Monte D. Hilarij.

Huarte de San Juan, Juan. 1989. Examen de ingenios para las ciencias. Edición de Guillermo Serés. Madrid: Cátedra.

Loyola, Ignacio de. 1952. Obras completas. Madrid: BAC.

Oropesa, Alonso de. 1979. Luz para conocimiento de los gentiles. Edición de Luis Díaz y Díaz. Madrid: Universidad Pontificia de Salamanca - Fundación Universitaria Española.

Valtanás, Domingo de. 1555. Doctrina Christiana, en casa de Martín de Montesdoca, Sevilla.

\section{BiBLIOGRAFÍA}

Ajo González y Sáinz de Zúñiga, Cándido María. 1957-1979. Historia de las universidades hispánicas. 11 vols. Madrid: Centro de Estudios e Investigaciones Alonso de Madrigal.

Arrizabalaga, Jon. 2018. «La medicina en Huarte de San Juan: práctica clínica versus filosofía natural». Cahiers de recherches médiévales et humanistes 35: 405-426.

Arrizabalaga, Jon. 2020. «Huarte de San Juan y la censura inquisitorial en la España de Felipe II». En Pasados y presente. Estudios paro el profesor Ricardo García Cárcel, ed. Rosa M.a Alabrús, José Luis Betrán, Javier Burgos, Bernat Hernández, Doris Moreno y Manuel Peña, 583-594. Bellaterra: Universitat Autònoma de Barcelona.

Bataillon, Marcel. 1955. "Jean d'Avila retrouvé». Bulletin Hispanique LVII (1-2): 5-44.

Bataillon, Marcel. 1995. Erasmo y España. México: Fondo de Cultura Económica.

Beltrán de Heredia, Vicente. 1968. Domingo de Báñez y las controversias sobre la gracia. Salamanca: CSIC.

Bjornson, Richard. 1973. "Guzmán de Alfarache: Apología for a Converso». Romanische Forschungen 85, 314-329.

Carande, Ramón. 1965. Carlos $V$ y sus banqueros. 2 vols. Madrid: Sociedad de Estudios y Publicaciones.

Caro Baroja, Julio. 1978. Los judíos en la España moderna y contemporánea. Madrid: Istmo.

Cessi, Roberto. 1957. «Paolinismo preluterano». En Rendiconti dell'Accademia nazionale dei Lincei. Classe di Scienze morali, storiche e filologiche, ser. VIII, XII, 3-30.

Fernández Cordero, María Jesús. 2018. «Juan de Ávila en la tradición de defensa de los conversos: la pertenencia al «linaje espiritual de Jesucristo». Miscellanea Comillas 76: 113-133.

García Ballester, Luis. 1995. "Artifex factivus sanitatis: health and medical care in medieval Latin Galenism». En Knowledge and the scholarly medical traditions, ed. Don Bates, 127-150. Cambridge: Cambridge University Press.

García Villoslada, Ricardo. 1970. «El paulinismo de Juan de Ávila». Gregorianum 51: 615-646.

Giglioni, Guido. 2018. «Between Galen and St. Paul: how Juan Huarte de San Juan responded to inquisitorial censorship». Early Science and Medicine 23: 114-134.

Giordano, Maria Laura. 2004. Apologetas de la fe. Elites conversas entre Inquisición y Patronazgo en España (siglos XV y XVI). Madrid: FUE.

Giordano, Maria Laura. 2010. "La ciudad de nuestra conciencia": los conversos y la construcción de la identidad judeocristiana
(1449-1556)». Hispania Sacra 52: 43-91. https://doi.org/10.3989/ hs.2010.v62.i125.243

Giordano, Maria Laura. 2014. «Nel nome di Paolo: umanesimo biblico e risonanze converse in Isabel de la Cruz e María de Cazalla (15121534)». En Donne e Bibbia nella crisi dell'Europa cattolica (secoli XVI-XVII), ed. Adriana Valerio y Maria Laura Giordano, 49-70. Trapani: Il pozzo di Giacobbe.

Giordano, Maria Laura. 2018a. "The Virus in the Language: Alonso de Cartagena's Deconstruction of the "Limpieza de Sangre" in Defensorium Unitatis Christianae (1450)». Medieval Encounters 24: 226-251.

Giordano, Maria Laura. 2018b. "Como águilas nos avemos de renovar": reforma de la Iglesia y beneficio de Cristo en Hernando de Talavera (1475-1507)». eHumanista/Conversos 6: 94-110.

Giordano, Maria Laura. 2018c. "La reforma católica que no pudo ser. Los comentarios al Catechismo de la Doctrina Christiana de Bartolomé de Carranza». En Reforma y Disidencia religiosa, ed. Michel Boeglin, Ignasi Fernández Terricabras y David Kahn, 127143. Madrid: Colección de la Casa de Velázquez.

Giordano, Maria Laura. 2020. "Cuando los católicos eran paulinos. Diego Pérez de Valdivia e Hipólita de Jesús en Barcelona (15781624)». En Reforma católica y disidencia conversa. Diego Pérez de Valdivia e Hipólita de Jesús en Barcelona (1578-1624), ed. Maria Laura Giordano, 33-106. Vigo: Academia del Hispanismo.

Giordano, Maria Laura. En prensa. «¿Una catequesis también para dudosos, conversos y renegados? Un sermón inédito de Diego Pérez de Valdivia».

Gracia Guillén, Diego. 1984. «Judaísmo, medicina y 'mentalidad inquisitorial' en la España del siglo XVI». En Inquisición española y mentalidad inquisitorial. Ponencias del Simposio Internacional sobre Inquisición, Nueva York, abril de 1983, ed. Ángel Alcalá, 328-352. Barcelona: Ariel.

Gutiérrez Nieto, Juan Ignacio. 1990. «El reformismo social de Olivares: el problema de la limpieza de sangre y la creación de una nobleza de mérito». En La España del Conde Duque de Olivares, ed. John Elliott y Ángel García Sanz, 417-442. Valladolid: Universidad.

Hernández Franco, Juan. 2014. «Síntomas de decadencia y el 'Discurso' de Juan Roco Campofrío (c. 1625) sobre la reforma de los estatutos de limpieza de sangre». Hispanic Reseach Journal 15(6): 477-491.

Hernández Franco, Juan y Pablo Ortega del Cerro. 2016. «Renovar la sociedad desde la idealización del veteroconverso. La propuesta de abrogación de los estatutos de limpieza de sangre de Fernando de Valdés». e/Humanista/Conversos 4: 22-37.

Huerga, Álvaro. 1978a. Los alumbrados de Baeza. Jaén: Instituto de Estudios Giennenses.

Huerga, Álvaro. 1978b. Historia de los alumbrados. I. Los alumbrados de Extremadura (1570-1582). Madrid: Fundación Universitaria Española.

Huerga, Álvaro. 1978c. Historia de los alumbrados. II. Los alumbrados de la Alta Andalucía (1575-1590). Madrid: Fundación Universitaria Española.

Iriarte, M. de. 1948. El doctor Huarte de San Juan y su Examen de Ingenios. Contribución a la historia de la psicología diferencial. Madrid: CSIC.

Irigoyen López, Antonio. 2010. «Religión católica y estatutos de limpieza de sangre». Sefarad 70(1): 141-170. https://doi. org/10.3989/sefarad.010.005

Kaplan Szyld, Axel. 2019. «Motivos judeo-cristianos en el pensamiento de Fray Luis de Granada (1504-1588)». Cadernos de Estudos Sefarditas 20: 81-99.

Kimmel, Seth. 2016. "Tropes of expertise and converso unbelief: Huarte de San Juan's History of Medicine». En After conversión. Iberia and emergence of modernity, ed. Mercedes García Arenal, 336-357. Leiden: Brill.

López Piñero, José María. 1979. Ciencia y técnica en la sociedad española de los siglos XVI y XVII. Barcelona: Labor.

Mandressi, Rafael. 2016. "Los mejores médicos de la tierra. El "pueblo de Israel" en el Examen de ingenios de Juan Huarte (1575)». Anuario colombiano de Historia social y de la cultura 43(2): 59-87.

Márquez Villanueva, Francisco. 2000. «Vida y escritos de Juan de Ávila a la luz de sus tiempos». En El maestro Ávila. Actas del congreso internacional, 77-98. Madrid: Conferencia episcopal española. 
Méchoulan, Hernry. 1979. Le sang de l'autre ou l'honneur de Dieu. París: Fayard.

Mondéjar, José. 1984. «El pensamiento lingüístico del doctor Huarte de San Juan». Revista de Filología Española 64(1): 71-128.

Morreale, Margherita. 1986. "Juan y Alfonso de Valdés, de la letra al espíritu». En El erasmismo en España, ed. Manuel Revuelta Sañudo y Ciriaco Morón Arroyo, 417-427. Santander: Sociedad Menéndez Pelayo.

Muñoyerro, Luis Alonso. 1945. La Facultad de Medicina en la Universidad de Alcalá de Henares. Madrid: CSIC.

Nirenberg, David. 2012. «Discourses of judaizing and judaism in Medieval Spain». La Corónica. A Journal of Medieval Hispanic Languages 41(1): 211-242.

Pastore, Stefania. 2003. Il vangelo e la spada. L'Inquisizione di Castilla e i suoi critici (1460-1598). Roma: Edizioni di Storia e Letteratura.

Pastore, Stefania. 2004. Un'eresia spagnola. Spiritualità conversa, alumbradismo e Inquisizione (1449-1559). Firenze: Olscki.

Pérez Aguilera, Paulina Ma. 2005. "De Sacra ratione concionandi, de Diego Pérez de Valdivia (Baeza, 1524-Barcelona, 1589)». Boletín del Instituto de Estudios Giennenses 191: 119-135.

Peset Reig, José Luis. 2000. «Las críticas a la universidad de Juan Huarte de San Juan». En Las universidades hispánicas: de la monarquía de los Austrias al centralismo liberal. V Congreso Internacional sobre Historia de las Universidades Hispánicas. Salamanca, 1998. I. Siglos XVI y XVII, ed. Luis E. Rodríguez-San Pedro Bezares, 387-395. Salamanca: Universidad de Salamanca - Junta de Castilla y León.

Pulido Serrano, Juan Ignacio. 2006. «Las negociaciones con los cristianos nuevos en tiempos de Felipe III a la luz de algunos documentos inéditos (1598-1607)». Sefarad 66 (2): 345-376. https://doi. org/10.3989/sefarad.2006.v66.i2.414

Quilliet, Bernard. 2007. L'acharnement théologique. Histoire de la grâce en Occident (III-XXI siècle). París: Fayard.

Revah, Israel Salvator. 1971. "La controverse sur les statuts de pureté de sang. Un document inédit: "Relación y consulta del cardenal Guevara sobre el negocio de Fray Agustín Saluzio" (Madrid, 13 août 1600)». Bulletin Hispanique 73(3/4): 263-306.

Rincón González, M.a Dolores. 2006. «Criterios de selección en la Universidad de Baeza: Huarte de San Juan y los planteamientos avilistas: Quod natura not donat, Academia non praestat, enim vero labor omnia vincit improbus». Elucidario: Seminario biobibliográfico Manuel Caballero Venzalá 1: 135-146.

Sáez, Ricardo. 1989. «Huarte de San Juan o el nacimiento de la conciencia crítica». Huarte de San Juan 1: 81-95.

Sáez, Ricardo. 2003. «L'Examen des esprits: un projet politique et social pour l'Espagne de Philippe II». En Juan Huarte au XXIe siècle. Actes de colloque, ed. Véronique Duché-Gavet, 37-51. Anglet: Atlantica.

Sánchez Gómez, Juan M. 1949. «Un discípulo del P. Mtro. Ávila en la Inquisición de Córdoba. El Dr. Diego Pérez de Valdivia, catedrático de Baeza». Hispania 9: 104-134.

Sicroff, Albert. 1960. Les controversies des statuts de "pureté de sang» en Espagne du XV su XVII siècle. París: Didier.

Stuczynski, Claude. 2012. «Pro converso apologetics and biblical exegesis». En The Hebrew Bible in Fifteenth century Spain, 151-176, eds. Jonathan Decter y Arturo Prats. Leiden-Boston: Brill.

Stuczynski, Claude. 2014. «Judaicité et richesse dans l'apologetique des Conversos portugais: un argument contre culturel». Atalaya 14: https://doi.org/10.4000/atalaya.1295

Verdín Díaz, Guillermo. 1992. Alonso de Cartagena y el Defensorium unitatis Christianae. Universidad de Oviedo: Servicio de Publicaciones.

TABLA: Citas bíblicas en el EIC

\begin{tabular}{|c|c|c|}
\hline Antiquum testamentum & 86 & $52,8 \%$ \\
\hline Libri historici (total) & 42 & $25,8 \%$ \\
\hline Genesis & 15 & $9,2 \%$ \\
\hline Exodus & 10 & $6,1 \%$ \\
\hline Leviticus & 2 & \\
\hline Numeri & 1 & \\
\hline Deuteronomium & 1 & \\
\hline Pentateucum (subtotal) & 29 & $17,8 \%$ \\
\hline ludices & 1 & \\
\hline Reges & 9 & $5,5 \%$ \\
\hline Paralipomena & 1 & \\
\hline Judith & 2 & \\
\hline Libri didactici (total) & 40 & $24,5 \%$ \\
\hline Job & 1 & \\
\hline Psalmi & 11 & $6,7 \%$ \\
\hline Proverbia & 12 & $7,3 \%$ \\
\hline Ecclesiastes & 4 & \\
\hline Sapientia & 2 & \\
\hline Ecclesiasticus & 10 & 6,1 \\
\hline Libri prophetici (total) & 4 & $2,5 \%$ \\
\hline Isaias & 3 & \\
\hline Ezechiel & 1 & \\
\hline Novum Testamentum & 77 & $47,2 \%$ \\
\hline Libri historici & 51 & $31,3 \%$ \\
\hline Evangelium sec. Matheum & 24 & $14,7 \%$ \\
\hline Evangelium sec. Marcum & 7 & $4,3 \%$ \\
\hline Evangelium sec. Lucam & 10 & $6,1 \%$ \\
\hline Evangelium sec. Ioannem & 8 & $4,9 \%$ \\
\hline Actus apostolorum & 2 & \\
\hline \multicolumn{3}{|l|}{ Libri didactici } \\
\hline Epistolae Pauli & 24 & $14,7 \%$ \\
\hline ad Romanos & 7 & $4,3 \%$ \\
\hline ad Corinthios & 9 & $5,5 \%$ \\
\hline ad Galatas & 1 & \\
\hline ad Colossenses & 1 & \\
\hline ad timotheum & 3 & \\
\hline ad Titum & 1 & \\
\hline ad Hebraeos & 1 & \\
\hline (genérica) & 1 & \\
\hline \multicolumn{3}{|l|}{ Libri prophetici } \\
\hline Apocalypsis & 2 & $1,2 \%$ \\
\hline TOTAL & 163 & $100 \%$ \\
\hline
\end{tabular}

